\title{
Use of oral sodium phosphate colonic lavage solution by Canadian colonoscopists: Pitfalls and complications
}

\author{
A Chan MD FRCPC, W Depew BSc MD FRCPC, S Vanner MD MSc FRCPC
}

\begin{abstract}
A Chan, W Depew, S Vanner. Use of oral sodium phosphate colonic lavage solution by Canadian colonoscopists: Pitfalls and complications. Can J Gastroenterol 1997;11(4):334-338. Oral sodium phosphate $(\mathrm{NaP})$ has become an attractive alternative to polyethylene glycol (PEG) for colonic cleansing before colonoscopy, but it potentially has greater complications. This study surveyed members of the Canadian Association of Gastroenterology (CAG) to determine how these colonic lavage agents are used and what complications have been encountered. The Dillman survey technique produced responses from $67 \%$ of the 400 members who perform colonoscopy. For the larger out-patient group, respondents used $\mathrm{NaP}$ more frequently than PEG (46\% versus 35\%, respectively, $\mathrm{P}<0.015)$. Respondents used $\mathrm{NaP}$ and $\mathrm{PEG}$ with similar frequencies for the in-patient group (44\% versus $43 \%$ ). Of respondents using $\mathrm{NaP}, 45 \%$ reported excluding its use in patients with renal failure, $30 \%$ with heart disease, $13 \%$ with incomplete bowel obstruction and $9 \%$ with extreme age. Symptoms suggestive of hypovolemia were reported in $9 \%$ of those using $\mathrm{NaP}$ compared with $3 \%$ using PEG $(\mathrm{P}<0.02)$. Three patients receiving $\mathrm{NaP}$ developed acute renal failure. A greater proportion of those using $\mathrm{NaP}$ had small unexplained aphthous ulcers (16\%) and excessive luminal bubbling (24\%) compared with PEG users (3\%, $\mathrm{P}<0.00001$ and $14 \%, \mathrm{P}<0.03$, respectively). These data demonstrate that members of CAG use NaP more frequently than PEG as the colonic lavage solution before colonoscopy. A greater number reported complications with $\mathrm{NaP}$ versus $\mathrm{PEG}$, and a significant proportion of the respondents appeared to be unaware of the potential for these complications in specific clinical circumstances.
\end{abstract}

Key Words: Colonic lavage, Colonoscopy, Polyethylene glycol, Sodium phosphate

\section{Phosphate sodique par voie orale pour nettoyer le côlon : pièges et complications signalés par les colonoscopistes canadiens}

RÉSUMÉ : Le phosphate sodique oral (PNa) est devenu une solution de rechange attrayante au polyéthylèneglycol (PEG) pour le nettoyage du côlon avant la colonoscopie, mais pourrait s'accompagner de complications plus grandes. Cette étude porte sur un sondage auprès des membres de l'Association canadienne de gastro-entérologie (ACG) en vue de déterminer comment ces agents sont utilisés et quelles sont les complications de sont utilisation. Un questionnaire de Dillman a généré des réponses de $67 \%$ parmi les 400 membres qui effectuent des colonoscopies. Pour les patients externes, plus nombreux, les répondants ont utilisé le PNa plus souvent que le PEG (46\%, contre $35 \%$ respectivement, $\mathrm{P}<0,015)$. Les répondants ont utilisé le $\mathrm{PNa}$ et le $\mathrm{PEG}$ à des fréquences similaires pour les patients hospitalisés ( $44 \%$, contre $43 \%$ ). Parmi les répondants ayant utilisé le $\mathrm{PNa}, 45 \%$ ont déclaré exclure son emploi chez les insuffisants rénaux et $30 \%$ chez les cardiaques, $13 \%$ en présence d'obstruction incomplète de l'intestin et $9 \%$ chez les patients très âgés. Des symptômes évocateurs d'une hypovolémie ont été signalés chez $9 \%$ de ceux qui utilisaient le $\mathrm{PNa}$, contre $3 \%$ pour ceux qui utilisaient le PEG $(\mathrm{P}<0,02)$. Trois patients ayant reçu du $\mathrm{PNa}$ ont présenté une insuffisance rénale aiguë. Une proportion plus grande de ceux qui utilisaient le $\mathrm{PNa}$ ont présenté de petits ulcères aphteux inexpliqués $(16 \%)$ et la présence de mousse intraluminaire excessive ( $24 \%$ ) en comparaison avec les utilisateurs de PEG ( $3 \%, \mathrm{P}<0,00001$ et $14 \%, \mathrm{P}<0,03$ respectivement). Ces données démontrent que les membres de l'ACG utilisent plus souvent le PNa que le PEG pour préparer le côlon avant la colonoscopie. Un nombre plus grand de complications ont été signalées avec le PNa qu'avec le PEG et une proportion significative de répondants ont semblé ignorer les complications potentielles dans certains cas cliniques spécifiques.

GI Diseases Research Group, Queen's University, Kingston, Ontario

Correspondence and reprints: Dr S Vanner, Division of Gastroenterology, 166 Brock Street, Kingston, Ontario K7L 5 G2.

Telephone 613-544-3310, fax 613-544-3114, e-mail svepost@queensu.ca

Received for publication June 4, 1996. Accepted September 25, 1996 
$\mathrm{O}$ al sodium phosphate $(\mathrm{NaP})$, a small volume osmotic cathartic, has recently been recommended as a colonic cleansing agent before colonoscopy (1-5). Because $\mathrm{NaP}$ has been shown to be better tolerated by patients while being equally or more effective than conventional osmotically balanced polyethylene glycol (PEG) solutions (1-5) and less expensive $(1,6), \mathrm{NaP}$ has become an attractive alternative to the PEG solutions.

Widespread enthusiasm for $\mathrm{NaP}$ has been tempered by the issue of its safety. Several investigators $(1,3,6,7)$ have raised concerns about hypovolemia induced by its osmotic action and hyperphosphatemia because of its phosphate content. These investigators demonstrated that a number of patients develop biochemical and/or hemodynamic signs of contraction of the intravascular space, and almost all patients develop transient hyperphosphatemia. In the subjects evaluated these findings did not lead to clinically significant adverse effects. However, patients with renal failure, ileus, ascites, heart disease and extreme age were not included in these studies $(1,2,5-7)$. Given the nature of the potential side effects, it seemed prudent to advise caution in these patient groups and to recommend replacing $\mathrm{NaP}$-induced volume losses with intravenous physiological saline in in-patients with other comorbid medical conditions.

Despite these recommendations there have been both case reports (8) and anecdotal reports (personal communication) of serious complications with $\mathrm{NaP}$ when it was used inappropriately. Accordingly, we surveyed the membership of the Canadian Association of Gastroenterology (CAG) to determine how $\mathrm{NaP}$ was being used by colonoscopists and to estimate the occurrence of complications using $\mathrm{NaP}$ compared with conventional PEG colonic cleansing preparations.

\section{MATERIALS AND METHODS}

A one-page questionnaire concerning preferences and experience with colonic cleansing agents (Table 1) was mailed to all practising CAG members in Canada. The Dillman survey technique (9) was used to optimize response rates. Ethics approval was obtained from the Queen's University Human Ethics Committee.

Statistical comparisons were performed using the Fisher's exact test. Results are presented as odds ratios $( \pm 95 \% \mathrm{CI})$.

\section{RESULTS}

Questionnaires were returned by $74 \%$ of the 400 members surveyed. Twenty-seven (9\%) were excluded from analysis because either the respondents did not perform colonoscopy or the form was incomplete. Therefore, $67 \%$ of CAG contributed to the data analyzed in this study.

Preference for colonic cleansing agent: Respondents reported using $\mathrm{NaP}$ significantly more frequently than $\mathrm{PEG}$ in the out-patient group (Figure 1). Forty-six per cent reported using $\mathrm{NaP}$, compared with 35\% using PEG, more than $75 \%$ of the time $(\mathrm{P}<0.015$, odds ratio $=1.60[1.13-2.26])$. Of these respondents, $24 \%$ reported using $\mathrm{NaP}$ all the time whereas $19 \%$ reported using solely PEG. In contrast, there was no dif-
TABLE 1

Survey of colonic lavage for colonoscopy

1. Circle present use of specific lavage solution before colonoscopy

\begin{tabular}{|c|c|c|c|c|c|}
\hline \multicolumn{3}{|c|}{ IN-PATIENTS } & \multicolumn{3}{|c|}{ OUT-PATIENTS } \\
\hline $\begin{array}{l}\text { Golytely } \\
\text { (or } \\
\text { related } \\
\text { solutions) }\end{array}$ & $\begin{array}{c}\text { Oral } \\
\text { sodium } \\
\text { (phosphate) }\end{array}$ & $\begin{array}{c}\text { Others } \\
\text { (specify) }\end{array}$ & $\begin{array}{l}\text { Golytely } \\
\text { (or } \\
\text { related } \\
\text { solutions) }\end{array}$ & $\begin{array}{c}\text { Oral } \\
\text { sodium } \\
\text { (phosphate) }\end{array}$ & $\begin{array}{c}\text { Others } \\
\text { (specify) }\end{array}$ \\
\hline $100 \%$ & & $100 \%$ & $100 \%$ & $100 \%$ & $100 \%$ \\
\hline$>75 \%$ & $>75 \%$ & $>75 \%$ & $>75 \%$ & $>75 \%$ & $>75 \%$ \\
\hline $50 \%$ & $50 \%$ & $50 \%$ & $50 \%$ & $50 \%$ & $50 \%$ \\
\hline$<25 \%$ & $<25 \%$ & $<25 \%$ & $<25 \%$ & $<25 \%$ & $<25 \%$ \\
\hline $0 \%$ & $0 \%$ & $0 \%$ & $0 \%$ & $0 \%$ & $0 \%$ \\
\hline
\end{tabular}

2. List any patient groups in which you would avoid the use of: Golytely

Sodium phosphate

Others

3. List any complications encountered and their frequencies with the use of:

Golytely

Sodium phosphate

Others

4. Do you give intravenous rehydration in in-patients during lavage?

\begin{tabular}{cccccc}
\multicolumn{2}{c}{ Golytely } & \multicolumn{2}{c}{ Sodium phosphate } & \multicolumn{2}{c}{ Others } \\
Yes $\%$ & No & Yes $\%$ & No & Yes $\%$ & No
\end{tabular}

5. Have you had difficulty with bubbles within the lumen which would obscure your view of significant lesions?

\begin{tabular}{llllll}
\multicolumn{2}{c}{ Golytely } & \multicolumn{2}{c}{ Sodium phosphate } & \multicolumn{2}{c}{ Others } \\
\cline { 1 - 1 } & Nes $\%$ & Yes $\%$ & No & Yes $\%$ & No
\end{tabular}

6. Have you noticed any unexplained findings that might have been caused by the lavage solution used?

\begin{tabular}{llllll}
\multicolumn{2}{c}{ Golytely } & \multicolumn{2}{c}{ Sodium phosphate } & \multicolumn{2}{c}{ Others } \\
\cline { 1 - 1 } Yes $\%$ & No & Yes $\%$ & No & Yes $\%$ & No
\end{tabular}

7. Approximately how many colonoscopies per year do you perform?

Adults Pediatrics

ference between the proportions using $\mathrm{NaP}$ or PEG in inpatients. Fewer than $8 \%$ reported using an alternative agent to $\mathrm{NaP}$ or PEG more than $75 \%$ of the time.

Contraindications to the use of NaP and PEG: To avoid bias in reporting, respondents were asked to list contraindications to the use of $\mathrm{NaP}$ and $\mathrm{PEG}$ but were not provided with options (Table 1). Of those using $\mathrm{NaP}$ on at least some occasions $(73 \%)$, only $45 \%$ reported excluding its use in patients with renal failure, $30 \%$ with cardiovascular disease, $13 \%$ with incomplete (subacute) bowel obstruction and $9 \%$ with extreme age (Figure 2). Of the $72 \%$ who reported using PEG at least on some occasions, $22 \%$ reported that they excluded its use in those with advanced age, $21 \%$ with incomplete bowel 


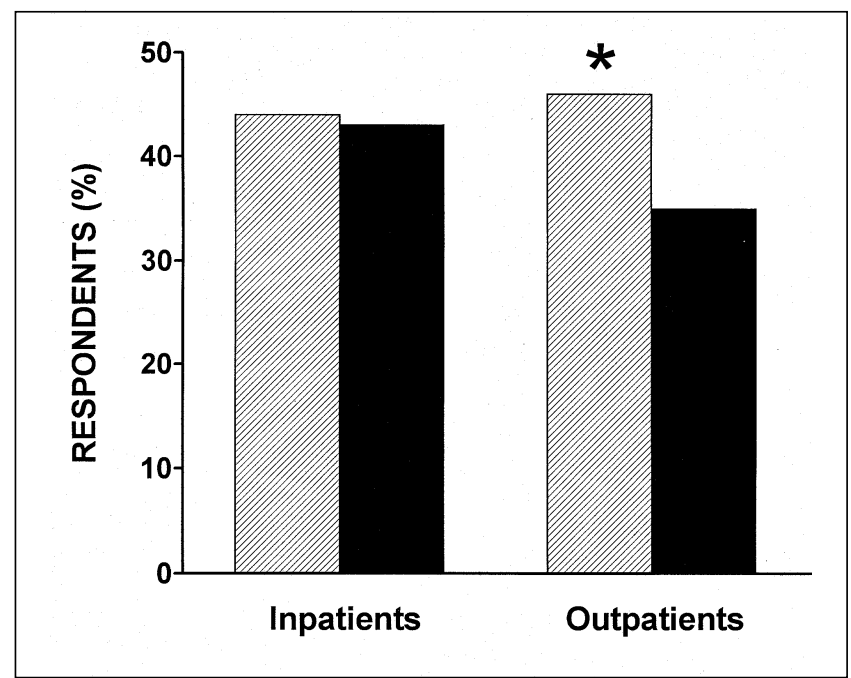

Figure 1) Oral sodium phosphate ( $\mathrm{NaP}$ ) was reported to be used more frequently for out-patient colonoscopy. The hatched bar shows percentage of respondents who use NaP more than $75 \%$ of the time for in- and out-patients. The solid bar designates percentage of respondents using PEG more than $75 \%$ of the time for in-and out-patients. *NaP is used significantly more frequently in the out-patient group $(P<0.015$, odds ratio $=1.60[1.13$ to 2.26$]$ )

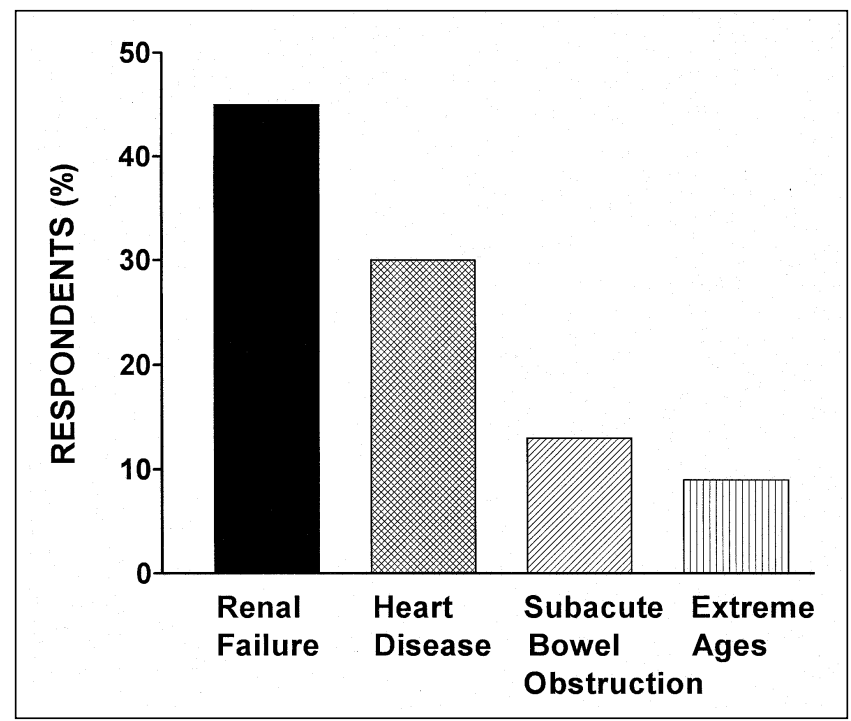

Figure 2) A large number of respondents appeared to be unaware of the contraindications to the use of oral sodium phosphate $(\mathrm{NaP})$. Each bar represents the percentage of respondents who reported renal failure, significant heart disease, subacute (incomplete) bowel obstruction or extreme age as a contraindication to the use of NaP. No specific option was listed on the questionnaire (see Table 1) to avoid bias reporting

obstruction, $16 \%$ with cardiovascular disease and $6 \%$ with renal failure.

Complications encountered and the use of intravenous rehydration: Significantly more respondents reported that they had treated patients who had experienced symptoms suggestive of clinically significant hypovolemia with $\mathrm{NaP}$ versus PEG ( $9 \%$ versus $3 \%, \mathrm{P}<0.02$, odds ratio $=3.12$ [1.23-8.05]) (Figure 3). Ten per cent using $\mathrm{NaP}$ and $5 \%$ using

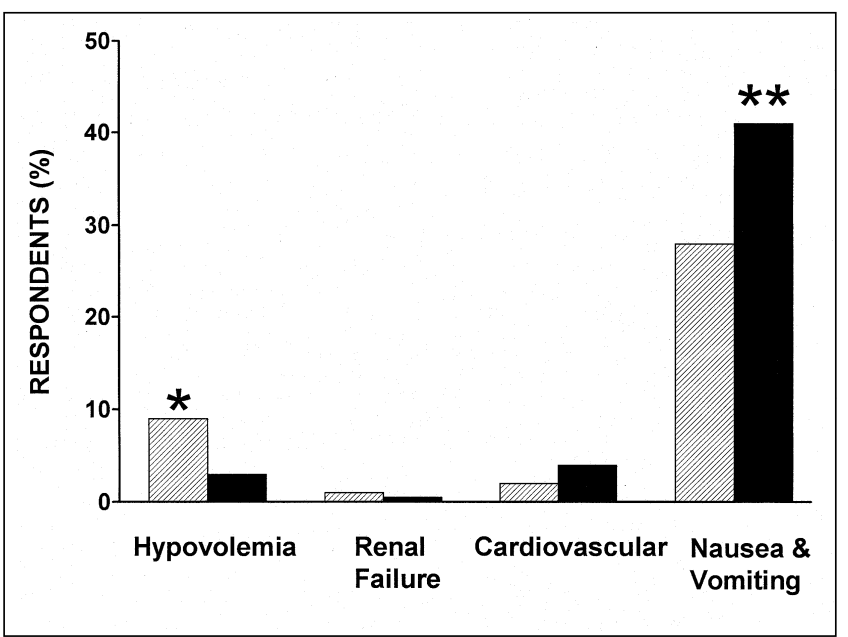

Figure 3) A significantly greater number of respondents reported patients having problems suggestive of hypovolemia with oral sodium phosphate (NaP) compared with polyethylene glycol (PEG). Hatched bars represent the percentage of respondents using $\mathrm{NaP}$ who reported problems with hypovolemia, renal failure, cardiovascular disease, and nausea and vomiting. Solid bars designate responses of those using PEG. *Hypovolemia was significantly more common with $\mathrm{NaP}$ than $\mathrm{PEG}(\mathrm{P}<0.02$, odds ratio $=3.15$ [1.23-8.05]);** Nausea and vomiting were significantly more common with $\mathrm{PEG}$ than $\mathrm{NaP}(P<0.02$, odds ratio $=0.60[0.41-0.90])$

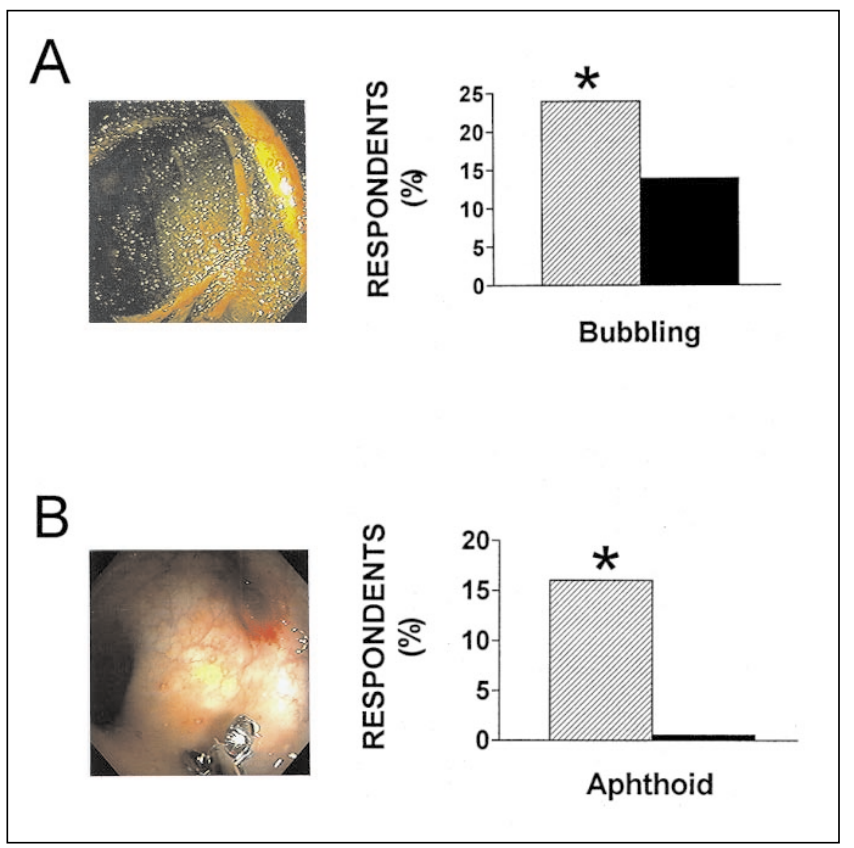

Figure 4) Unexplained aphthous ulcers and bubbling were more common with oral sodium phosphate ( $\mathrm{NaP}$ ) than polyethylene glycol (PEG). 4A Left Videophotographic image of luminal bubbling. 4A Right Number of respondents who considered luminal bubbling to be a problem on at least some occasions with oral sodium phosphate ( $\mathrm{NaP}$ ) (hatched bar) compared with polyethylene glycol (PEG) (solid bar) $(* P<0.03$, odds ratio $=1.85$ [1.11-3.08]). 4B Left Videophotographic image of unexplained aphthous lesions, which have been associated with NaP use. Tip to tip distance of the biopsy instrument is $7 \mathrm{~mm}$. Biopsy of the lesion demonstrated nonspecific acute inflammation. 4B Right Percentage of respondents who had observed this problem with $\mathrm{NaP}$ (hatched bar) compared with PEG (solid bar) $(P<0.0001$, odds ratio $=36.22$ [4.91267.26] 
PEG used intravenous rehydration on at least some occasions in in-patients during colonic lavage. Three patients were felt to have developed acute renal failure related to their use of $\mathrm{NaP}$ versus one patient following PEG use. Cardiovascular complications were reported in $2 \%$ using $\mathrm{NaP}$ and $4 \%$ using PEG. Nausea and vomiting were reported by a larger proportion of colonoscopists with PEG compared with $\mathrm{NaP}$ (41\% versus $28 \%)(\mathrm{P}<0.02$, odds ratio $=0.60[0.41-0.90])$.

Excessive luminal bubbling and unexplained aphthous lesions: $\mathrm{NaP}$ may cause intraluminal bubbling, which might obscure the mucosal detail in some patients (Figure 4). Twenty-four per cent of those using $\mathrm{NaP}$ reported that they had observed this phenomenon on at least some occasions, compared with $14 \%$ using PEG $(\mathrm{P}<0.03$, odds ratio $=1.85$, [1.11-3.08]). NaP lavage had also been associated with minute mucosal aphthoid lesions (10); these might lead to diagnostic confusion in some patients (Figure 4). Sixteen per cent of respondents reported seeing these lesions when using $\mathrm{NaP}$ compared with $1 \%$ using $\mathrm{PEG}(\mathrm{P}<0.0001$, odds ratio $=$ $36.22[4.91-267.26])$.

\section{DISCUSSION}

Results of this survey suggest that in Canada $\mathrm{NaP}$ is now used more frequently than PEG for colonic lavage before outpatient colonoscopy. Because this is a much larger patient group compared with the in-patient colonoscopy group, these data suggest that overall $\mathrm{NaP}$ has become the preferred colonic cleansing agent. The data also suggest that patients receiving $\mathrm{NaP}$ may experience more lavage-related complications. Most important, many colonoscopists using this agent may not be fully aware of its potential for such complications.

In designing our survey (see Table 1) a one-page format was chosen to minimize reporting bias and maximize response rate, recognizing that it would limit the nature and detail of the conclusions that could be drawn. The survey was deliberately devised so that respondents would not be alerted to the fact that we were most interested in their use of $\mathrm{NaP}$. To obtain an unbiased appraisal of the respondents' working knowledge of complications and contraindications, specific events were purposely not listed on the survey form.

Despite evidence that $\mathrm{NaP}$ lavage can produce intravascular volume depletion and hyperphosphatemia $(1,3,6,7)$, albeit clinically insignificant in patients who are otherwise well (7), and despite recommendations that this agent be avoided in patients with renal failure, cardiovascular disease, incomplete bowel obstruction and extreme age (7), a surpris-

ACKNOWLEDGEMENTS: This study was supported in part by an education grant from Pharma Science, Montreal, Quebec.

\section{REFERENCES}

1. Vanner SJ, MacDonald PH, Paterson WG, Prentice RS, DaCosta LR, Beck IT. A randomized prospective trial comparing oral sodium phosphate with standard polyethylene glycol-based solution (Golytely) in the preparation of patients for colonoscopy. Am J Gastroenterol 1990;85:422-7. ing number of respondents failed to list these as contraindications. It might be argued that the nature of this survey results in under-reporting of these contraindications. However, the fact that renal failure (the most frequently reported contraindication) was identified by only $45 \%$ of respondents makes it extremely unlikely that this alone accounts for the low percentage. It is more likely that, although this agent has continued to gain popularity because of patient acceptance and cost, a significant number of colonoscopists are not fully aware of its potential major complications. That a significantly greater number of respondents using $\mathrm{NaP}$ had patients experiencing symptoms suggestive of hypovolemia compared with those using PEG, and that three patients developed renal failure, also support this concern because studies that carefully excluded patients $(1,2,5-7)$ avoided these problems.

Colonoscopists should also be aware that $\mathrm{NaP}$ has also been reported to cause minor technical and interpretive difficulties. Several reports have suggested that tiny aphthoid lesions may be found in some patients $(10,11)$, which appear to result from the effects of $\mathrm{NaP}$ on the colonic mucosa. One study (11) examined the prevalence of these lesions after lavage with either $\mathrm{NaP}$ or $\mathrm{PEG}$ solution. Colonoscopists who were blinded to the type of lavage preparation used reported finding these lesions in $25 \%$ of patients $(n=53)$ receiving $\mathrm{NaP}$ compared with $2 \%$ receiving PEG $(\mathrm{n}=44)$. Macroscopically these lesions may raise a suspicion of Crohn's disease but biopsies demonstrate only a nonspecific acute inflammatory infiltrate. In the present study a relatively small number of colonoscopists (16\%) reported observing such lesions. A randomized blinded study also suggested that in some patients $\mathrm{NaP}$ may create bubbling in the lumen that may obscure visualization of the mucosa. Bubbling was noted to be a problem by only a minority of respondents in our study (24\%). Simethicone has been shown to resolve this problem almost completely (12).

\section{CONCLUSIONS}

This survey suggests that $\mathrm{NaP}$ has become the preferred agent for colonic cleansing among CAG members. Their responses suggest that many are unaware of some of the potential complications of this agent. Reports of increased hypovolemia and renal failure with $\mathrm{NaP}$ support previous recommendations that $\mathrm{NaP}$ be avoided in patients with renal failure, significant cardiovascular disease, incomplete bowel obstruction and extreme age, and that in-patients with ongoing medical problems receive intravenous rehydration during colonic lavage.

2. Koits BE, Lyles WE, Achem SR, Burton L, Geller AJ, MacMath T. A comparison of the effectiveness and patient tolerance of oral sodium phosphate, castor oil, and standard electrolyte lavage for colonoscopy or sigmoidoscopy preparation. Am J Gastroenterol 1993;88:1218-23.

3. Cohen SM, Wexner SD, Bindrow SR, et al. Prospective, randomized, endoscopic-blinded trial comparing precolonoscopy bowel cleansing methods. Dis Colon Rectum 1994;37:689-96.

4. Golub RW, Kerner BA, Wise WE, et al. Colonoscopic bowel preparations - which one? A blinded, prospective, randomized trial. Dis Colon Rectum 1995;38:594-9. 
5. Marshall JB, Pineda JJ, Barther JS, King PD. Prospective randomized trial comparing sodium phosphate solution with polyethylene glycol-electrolyte lavage for colonoscopy preparation. Gastrointest Endosc 1993;39:631-4

6. Afridi SA, Barthel JS, King PD, Pineda JJ, Marshall JB. Prospective randomized trial comparing a new sodium phosphate-biscodyl regimen with conventional PEG-ES lavage for outpatient colonoscopy preparation. Gastrointest Endosc 1995;41:485-9.

7. Huynh T, Vanner S, Paterson W. Safety profile of 5 -h oral sodium phosphate regimen for colonoscopic cleansing: Lack of clinically significant hypocalcemia or hypovolemia. Am J Gastroenterol 1994;90:104-7.

8. Fass R, Son Do M, Hixson L. Fatal hyperphosphatemia following Fleet
Phospo-Soda in a patient with colonic ileus. Am J Gastroenterol 1993;88:929-32.

9. Dillman DA. Mail and Telephone Surveys: The Total Design Method. New York: John Wiley and Sons, 1978.

10. Hixson L. Colorectal ulcers associated with sodium phosphate catharsis. Gastrointest Endosc 1995;42:10-2.

11. El-Serag H, Zwas F, Cirillo D. Colonic mucosal abnormalities associated with bowel preparations. Gastrointest Endosc 1995;42:A96.

12. Sudduth R, DeAngelis S, Sherman K, McNally P. The effectiveness of simethicone in improving visibility during colonoscopy when given with a sodium phosphate solution: a double-blind randomized study. Gastrointest Endosc 1995;42:413-6. 


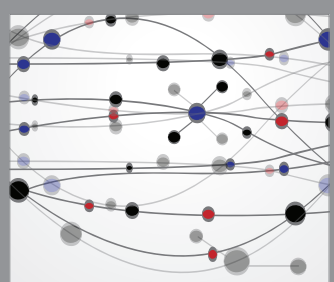

The Scientific World Journal
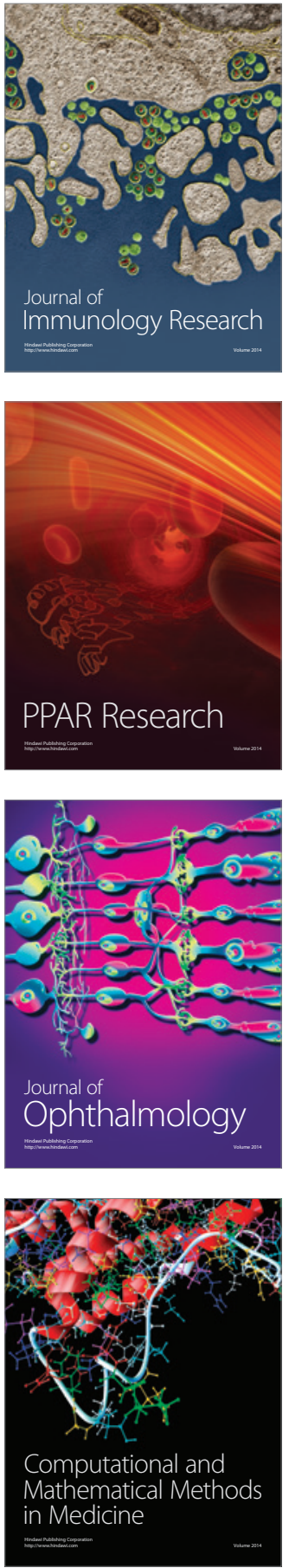

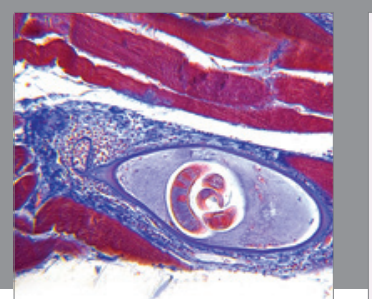

Gastroenterology Research and Practice

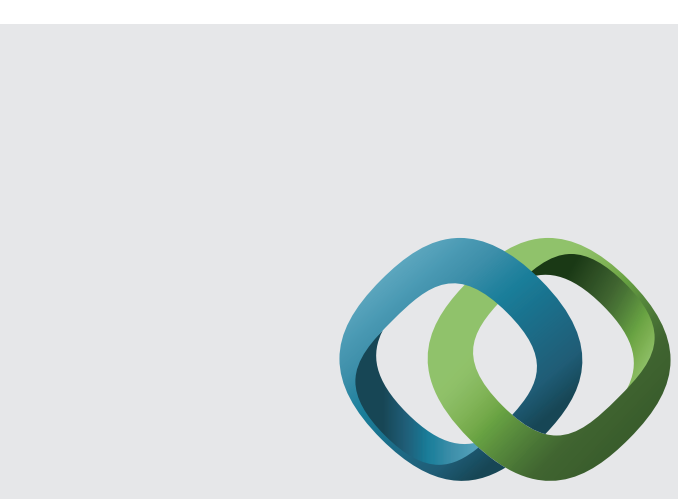

\section{Hindawi}

Submit your manuscripts at

http://www.hindawi.com
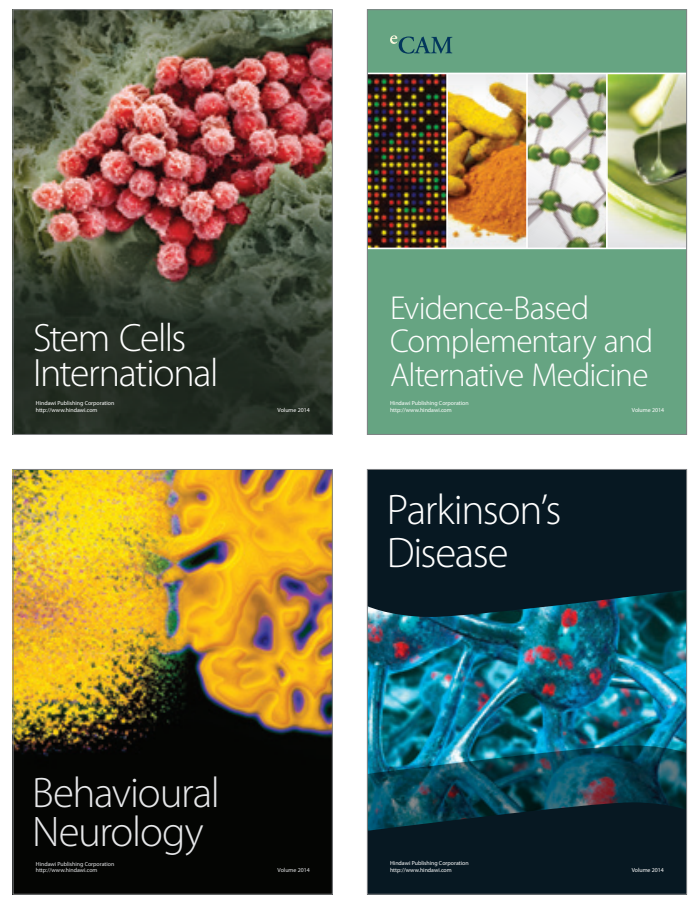
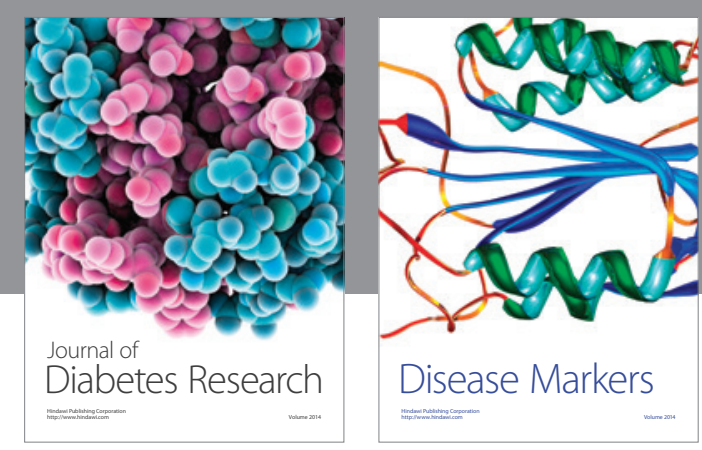

Disease Markers
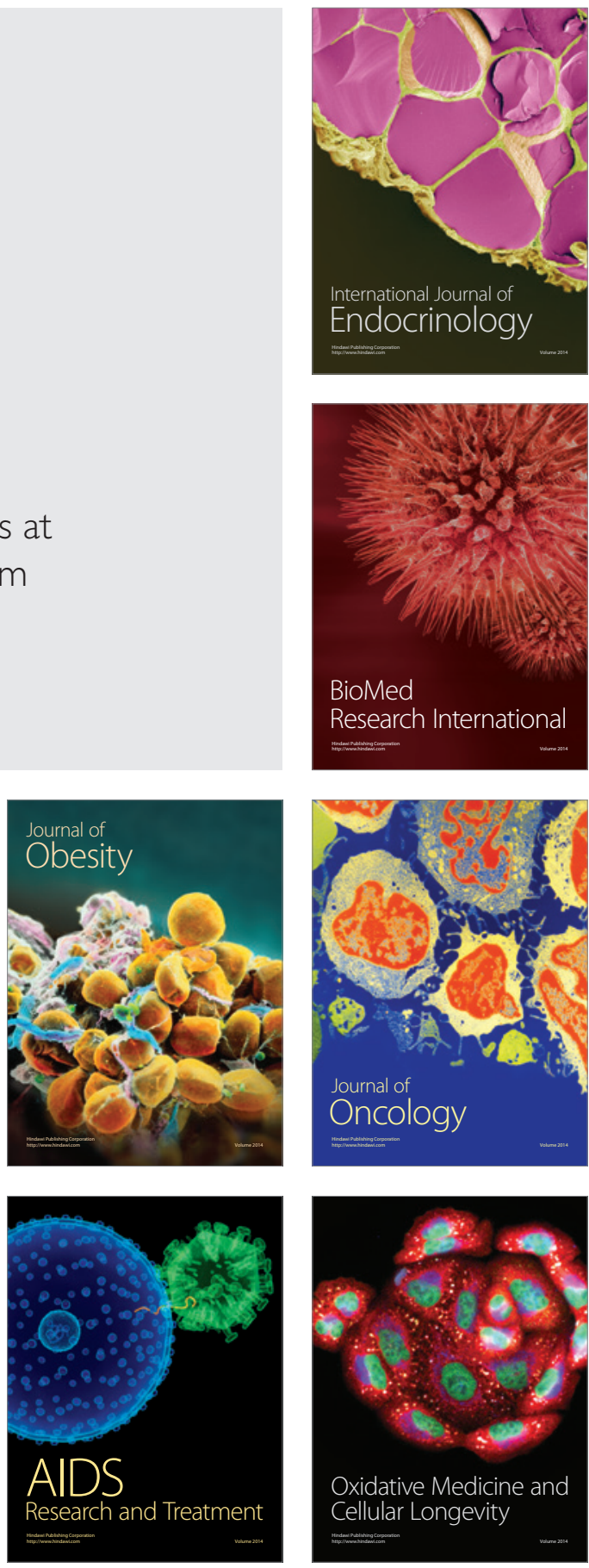